\title{
Bazı uçucu yağların çam kese böceğine [Thaumetopoea sp.) (Lepidoptera: Notodontidae )] karşı toksik etkilerinin araştırılması
}

Investigation of the toxic effects of some essential oils to pine processionary moth [Thaumetopoea sp. (Lepidoptera: Notodontidae)]

\author{
Şeyma Ẏ̇̆̆́̇T ${ }^{1}$ \\ İzzet $\mathrm{AKÇA}^{1}$ \\ İslam SARUHAN ${ }^{1}$ \\ Selime BAYHAN ${ }^{2}$ \\ Erol BAYHAN ${ }^{2}$ (D) \\ Fethullah TEKIN ${ }^{3}$
}

${ }^{1}$ Ondokuz Mayıs Üniversitesi, Ziraat Fakültesi, Bitki Koruma Bölümü, Samsun

${ }^{2}$ Dicle Üniversitesi, Ziraat Fakültesi, Bitki Koruma Bölümü, Diyarbakır

${ }^{3}$ GAP UluslararasıTarımsal Araştırma ve Eğitim Merkezi , Diyarbakır

Sorumlu yazar (Corresponding author) Şeyma YİĞiT

seyma.yigit@omu.edu.tr

Geliş tarihi (Received)

09.10.2019

Kabul tarihi (Accepted)

08.01.2020

Atıf (To cite this article): YíĞiT, S, AKCA, İ, SARUHAN, I , BAYHAN, S, BAYHAN, E, TEKINN, F . (2020). Bazı uçucu yağların çam kese böceğine [Thaumetopoea sp.) (Lepidoptera: Notodontidae )] karşı toksik etkilerinin araştırılması. Ormancilık Araștırma Dergisi , 7 (1), 76-79. DOI: https://doi.org/10.17568/ogmoad.631341

\section{Öz}

Orman ağaçlarında zarar yapan türlerin büyük bir bölümü ağaçların vejetatif kısımlarında zarar nedenolmakta ve dolayısıyla kayba neden olmaktadır. Thaumetopoea sp. (Lepidoptera: Notodontidae) bu türlerden birisi olup özellikle çam ağaçlarında ciddi zarara neden olmaktadır. Bu zararlı ile sadece mekanik, biyolojik ve kimyasal mücadele yapılmaktadır. Fakat kimyasal mücadelenin ekosistem ve hedef dış1 bir çok canlıya olan zararlı etkilerinden dolayı alternatif mücadele yöntemlerinin kullanılması kaçınılmazdır. Bu çalışmada Rosmarinus officinalis, Teocrium polium ve Sideritis libanotica bitkilerinden elde edilen uçucu yağların üç farklı dozu (\%0,1; \%0,5 ve \%1,0) çam kese böceği larvalarına uygulanmıştır. Denemeler laboratuvar şartlarında (\%65 \pm 5 nem ve $25 \pm 5^{\circ} \mathrm{C}$ sicaklık) yürütülmüştür. Uygulamadan 5 gün sonra ölen larvalar sayılarak yağların zararlıya karşı toksik etkileri belirlenmiştir. Çalışmada uçucu yağların en yüksek doz olan $\% 1$ dozunda Sideritis libanotica, Rosmarinus officinalis ve Teocrium polium'da ölüm oranları sırasıyla $\% 70, \% 60$ ve $\% 50$ olarak bulunmuştur. Her üç yağda $\mathrm{LC}_{90}$ değerleri ise sırasıyla 1,462; 1,702 ve 1,912 olarak belirlenmiş̧tir. Sonuç olarak, çalışmada kullanılan üç yağ arasından Sideritis libanotica çam kese larvalarının mücadelesinde ümitvar olarak görülmektedir.

Anahtar Kelimeler: Çam kese böceği, uçucu yağ, Sideritis libanotica, Rosmarinus officinalis, Teocrium polium, Thaumetopoea sp.

\begin{abstract}
Most of the species that damage the forest trees leads to the damage and thus loss of the vegetative parts of the trees and thus cause loss. Thaumetopoea sp. (Lepidoptera: Notodontidae) is one of these species and causes serious damage, especially in pine trees. This pest is controlled only mechanically, biologically and chemically. However, it is necessary to use alternative control methods because of the harmful effects of chemical control on ecosystem and many nontarget organisms. In this study, three different doses $(0.1 \% ; 0.5 \%$ and $1.0 \%)$ of the essential oils obtained from Rosmarinus officinalis, Teocrium polium and Sideritis libanotica plants were applied to pine processionary moth. The experiments were carried out under laboratory conditions ( $65 \pm 5 \%$ humidity and $25 \pm 5^{\circ} \mathrm{C}$ temperature). The larvae that died 5 days after the application were counted and the toxic effects of the oils against the pests were determined. In the study, the mortality rate of Sideritis libanotica, Rosmarinus officinalis and Teocrium polium was found to be $70 \%, 60 \%$ and $50 \%$ respectively. $\mathrm{LC}_{90}$ values of three oils were determined as 1.462, 1.702 and 1.912 respectively. In conclusion, among the three oils used in the study, Sideritis libanotica is considered as promising in the control of pine processionary moth.
\end{abstract}

Key Words: Pine processionary moth, essential oil, Sideritis libanotica, Rosmarinus officinalis, Teocrium polium, Thaumetopoea sp. 


\section{Giriş}

Çam kese böceği (Thaumetopoea sp.) ülkemiz ormanlarının büyük bir kısmını oluşturan çam türlerinde iğne yaprakları yemek suretiyle ağaçların zarar görmesine neden olması bakımından önemli bir zararlıdır. Çam kese böceği bu zarar1nın yanı sıra, ağacın zayıflamasına neden olarak sekonder zararlılar için uygun bir ortam oluşmaktadır. Ayrıca gelişmiş larvalar insanlarda ve evcil hayvanlarda solunum yetersizliği, konjuktivit ve astım gibi alerjik reaksiyonlara neden olmaktadır (Ekerbiçer ve ark., 2002; Kanat, 2002; Battisti ve ark., 2011). Bu zararlı Türkiye orman alanlarında yaklaşı1k \%60'lara varan kayıplara neden olmaktadır (Kanat ve ark., 2002; Kanat ve Alma, 2004). Bu zararlıya karşı tedbir alınmadığında ormanlarda yüksek oranda ağaç ölümlerine neden olabilmektedir (Akkuzu ve Selmi, 2002; Avcı ve Oğurlu, 2002).

Çam kese böceğine karşı daha çok mekanik, biyolojik ve kimyasal mücadele yöntemleri uygulanmaktadır. Mekanik mücadele ile savaş ancak küçük alanlarda kullanım imkanı bulmasından dolay1 yetersiz kalmakta, kimyasal mücadelede kullanılan insektisitler (böcek öldürücüler) insanların ve diğer canlıların sağlığına olumsuz etki ederek doğada bulunan yararlı türlerin popülasyonlarının azalmasına neden olmaktadır. İnsektisitler kalıcı bir çözüm getirmediği için belirli periyotlarda tekrarlanması gerekmektedir. Kimyasal savaşın bu olumsuz etkileri karşısında ekolojik dengeye zarar vermeyen mücadele yöntemlerine (biyolojik mücadele, biyoteknik mücadele, vb.) verilen önem artmıștır. Zararlı mücadelesinde alternatif yöntemler içerisinde bitkisel yağlar önemli bir yer tutmaktadır. Bitkisel yağlar, doğada bulunmaları dolayısıyla doğaya ek toksik madde yaymalarının söz konusu olmaması, kısa sürede dekompoze oldukları için toprak ve su kirliliklerine neden olmamaları, ürünler üzerinde insan sağlığını tehdit eden kalıntı oluşturmamaları, spesifik olmaları gibi nedenleri ile zararlı mücadelesinde tercih edilmektedir.

Bu yağlar zararlılara karşı öldürücü etkinin yanı sıra uzaklaştırıcı, zararlının gelişme ve üremesini de engelleyici olarak ta etki gösterebilmektedirler (Isman 2000; Papachristos ve ark., 2004; Petrakis, 2005; Isman, 2000). Bu yağların zararlı mücadelesinde tercih edilmesinin en önemli nedenleri arasında memelilere karşı olan düşük toksisitesi ve çevreye bilinen zararlı etkilerinin olmayışı da bulunmaktadır (Rabenhorst 1996; Misra ve Pavlostathis, 1997; Isman, 2000). Bitkisel yağların tarımsal alanlarda farklı zararlılara karşı insektisit etkisi üzerine bir çok çalışma bulunmasına rağmen, Çam kese böceğine karşı öldürücü etkisi üzerine çalış- ma oldukça sınırlıdır (Kanat ve Alma, 2004; Çetin ve Yanıkoğlu., 2006; Kesdek ve ark., 2014; Yiğit ve ark., 2019a, Yiğit ve ark., 2019b).

$\mathrm{Bu}$ çalışmada Rosmarinus officinalis, Teocrium polium ve Sideritis libanotica bitkilerinden elde edilen uçucu yağların Thaumetopoea sp. larvaları üzerindeki öldürücü etkisi araştırılmıştır.

\section{Materyal ve Metot}

Bu çalışma Samsun Ondokuz Mayıs Üniversitesi, Ziraat Fakültesi, Bitki Koruma Bölümüne ait laboratuvarda kontrollü koşullarda $\left(25 \pm 5^{\circ} \mathrm{C}\right.$ sicaklık ve $\% 65 \pm 5$ orantılı nem) yürütülmüştür.

Araştırmada Diyarbakır ekolojik koşullarında yetiştirilmiş farklı bitkilerden elde edilen uçucu yağlar (Rosmarinus officinalis, Teocrium polium ve Sideritis libanotica) kullanılmıştır. Söz konusu bu bitkilerden Neo- Clevenger cihazı kullanılarak su buharı destilasyon yöntemi ile uçucu yağlar elde edilmiştir (Linskens ve Jackson, 1997). Thaumetopoea sp. larvaları, Ondokuz Mayıs Üniversitesi kampüs alanındaki kızıl çam ağaçlarından (Pinus brutia) toplanmıştır.

Deneme aynı yaştaki larvalara karşı, her uçucu yağ türünün farklı dozları $(\% 0,1 ; \% 0,5$ ve $\% 1,0)$ için 4 tekerrürlü olarak kurulmuş ve $10 \times 10 \mathrm{~cm}$ boyutlarındaki plastik kaplarda yürütülmüştür. Bu kaplar içerisinde saf su ile nemlendirilmiş kurutma kağıtları konulmuş ve larvaların beslenmesi için belli miktarda çam ibresi konulmuştur. Her bir plastik kaba 10 adet larva konulmuş, denemede kullanılan larvalar bir tek koloniden seçilmiştir. Çalışmada kullanılan uçucu yağların farklı dozlar1 $(\% 0,1 ; \% 0,5$ ve $\% 1,0)$ saf su ve $\% 0,3$ 'lük tween 80 (Emülgatör) kullanılarak hazırlanmıştır. Hazırlanan dozlar içerisine larva yerleştirilmiş plastik kaplara $5 \mathrm{ml}$ gelecek şekilde püskürtme yapılmıştır. Kontrol kutularına ise sadece saf su püskürtülmüştür. Uygulamadan 1, 3 ve 5 gün sonra her kaptaki ölü larvalar sayılmıştır. Elde edilen veriler Abbot formülü uygulanarak gerçek ölüm oranları (\% etki) belirlenmiştir (Abbott, 1925). Çalışmada ölüm konsantrasyonlarının $\left(\mathrm{LC}_{50}\right.$ ve $\mathrm{LC}_{90}$ ) belirlenmesi için Probit analiz programı kullanılmıştır. Elde edilen verilere tek yönlü varyans analizi uygulanmış ve ortalamalar arasındaki fark Duncan çoklu karşılaştırma testi ile belirlenmiştir. Sonuçların değerlendirilmesinde SPSS (ver. 21) paket programından yararlanılmıştır.

\section{Bulgular}

Çam kese böceği larvalarına karşı yapılan çalışmada ele alınan bitki türleri Sideritis libano- 
tica $\% 1$ dozunda $\% 70$ oranında etkili olup $\mathrm{LC}_{50}$ değeri 0,598 ve $\mathrm{LC}_{90}$ değeri 1,462 olarak görülmektedir. Teocrium polium $\% 1$ dozu $\% 50$ oranında etkili olurken $\mathrm{LC}_{50}$ değeri 0,910 ve $\mathrm{LC}_{90}$ değeri 1,912 bulunmuştur. Rosmarinus officinalis en yüksek dozunda ise ölüm oran1 \%60 olup, LC $_{50}$ değeri 0,776 ve $\mathrm{LC}_{90}$ değeri 1,702 dir (Tablo 1). Ancak bunların içerisinde, en etkili türün Sideritis libanotica ol- duğu tespit edilmiştir. Türler ayrı ayrı değerlendirildiğinde, dozlar arttıkça larva ölüm oranlarının arttığı gözlemlenmiştir. Tüm yağlarda dozlar kendi içerisinde değerlendirildiğinde, üst dozlar istatistiki olarak diğer dozlardan farklı grupta yer almıştır. S. libanotica'nın \%1 dozu incelendiği zaman $\mathrm{LT}_{50}$ değeri 4,126 bulunurken $\mathrm{LT}_{90}$ değeri 7,742 olarak bulunmuştur (Tablo 2).

Tablo 1. Bitkisel yağların $\mathrm{LC}_{50}$ ve $\mathrm{LC}_{90}$ değerleri

Table 1. $\mathrm{LC}_{50}$ and $\mathrm{LC}_{90}$ values of essential oils

\begin{tabular}{|c|c|c|c|c|}
\hline Bitki Türleri & Dozlar (\%) & Ortalama ölüm oran1 & $\mathrm{LC}_{50}$ & $\mathrm{LC}_{90}$ \\
\hline \multirow{4}{*}{ Rosmarinus officinalis } & 0 & $0,00 \pm 0,00 \mathrm{~d} * * \mathrm{~B}^{*}$ & \multirow{4}{*}{0,776} & \multirow{4}{*}{1,702} \\
\hline & 0,1 & $15,00 \pm 5,00 \mathrm{~cd} \mathrm{~B}$ & & \\
\hline & 0,5 & $40,00 \pm 8,16$ bc $A$ & & \\
\hline & 1 & $60,00 \pm 14,14 \mathrm{ab} \mathrm{A}$ & & \\
\hline \multirow{4}{*}{ Teocrium polium } & 0 & $0,00 \pm 0,00 \mathrm{~d} B$ & \multirow{4}{*}{0,910} & \multirow{4}{*}{1,912} \\
\hline & 0,1 & $10,00 \pm 5,77 \mathrm{~dB}$ & & \\
\hline & 0,5 & $40,00 \pm 16,32 \mathrm{bcA}$ & & \\
\hline & 1 & $50,00 \pm 5,77 \mathrm{ab} \mathrm{A}$ & & \\
\hline Sideritis libanotica & 0 & $0,00 \pm 0,00 \mathrm{~dB}$ & 0,598 & 1,462 \\
\hline
\end{tabular}

Tablo 2. Bitkisel yağların $\mathrm{LT}_{50}$ ve $\mathrm{LT}_{90}$ değerleri

Table 2. $\mathrm{LT}_{50}$ and $\mathrm{LT}_{90}$ values of essential oils

\begin{tabular}{cccc}
\hline Bitki türü & Dozlar (\%) & $\mathrm{LT}_{50}$ & $\mathrm{LT}_{90}$ \\
\hline \multirow{3}{*}{ Rosmarinus officinalis } & 0,1 & 8,343 & 12,610 \\
& 0,5 & 5,407 & 10,079 \\
& 1 & 4,113 & 9,440 \\
\hline \multirow{3}{*}{ Teocrium polium } & 0,1 & 16,687 & 29,038 \\
& 0,5 & 6,162 & 10,839 \\
& 1 & 5,244 & 10,754 \\
\hline \multirow{2}{*}{ Sideritis libanotica } & 0,1 & 7,249 & 11,079 \\
& 0,5 & 5,005 & 10,179 \\
& 1 & 4,126 & 7,742 \\
\hline
\end{tabular}

\section{Tartışma ve Sonuç}

Yiğit ve ark. (2019a) çam kese larvalarına karşı kekik türlerinden elde edilen uçucu yağların kullanımıyla \%70 - 90 arasında ölüm görülmüş olup, sonuçta kekik türlerinin çok etkili olduğu belirlenmiştir. Çalışma sonucunda düşük dozlarda bile uçucu yağ uygulamalarının etkili olduğu ve doz arttıkça etkinin arttığ1 görülmüştür. Bu çalışmada beş farklı kekik türüne ait uçucu yağların (Origanum majarona, Origanum multiflorum, Origanum saccatum, Thymus cillilus, Thymbra spicata) üç farklı dozu $(\% 0,1 ; \% 0,5$ ve \%1) dört tekerrürlü olarak Çam kese böceği larvalarına uygulanmıştır. Tüm yağların \%1 dozu değerlendirildiği zaman en yüksek ölüm oran1 T. cillius' da $\% 95$ olarak belirlenmiştir. Diğer türler ise etki oranlarına göre $O$. saccatum $(\% 90)$, T. spicata ve O. multiflorum $(\% 80)$ ve O. majarona $(\% 75)$ şeklinde sıralanmıştır.

Yiğit ve ark. (2019b) çam kese larvalarına karş1 bazı ticari yağların uygulanması çalışmalarında; çalışmanın 5. gününde, $\% 1$ dozunda kekik yağ 1 $\% 100$ ölüm oranı ile en etkili olurken, bunu haşhaş (\%95), adaçayı (\%95), sarımsak (\%90), biberiye $(\% 70)$, çam $(\% 60)$ ve nane $(\% 40)$ izlemiştir. Çalışmada kullanılan lavanta yağı ise etkisiz kalmıştır. Çalışma sonucunda kekik, haşhaş, adaçayı ve 
sarımsak yağlarının Çam kese böceği larvalarına karşı etkili olduğu ve bu zararlının kontrolünde kullanılabilecek potansiyele sahip oldukları tespit edilmiştir. Ayrıca biberiye, çam, nane ve lavanta yağlarının daha az etkili olduğu bulunmuştur.

Kanat ve Alma (2004) yaptıkları çalışmada; 9 farkl1 uçucu yağ çeşidini (P. brutia Ten, Laurus nobilis L., Liquidambar orientalis Miller, Juniperus communis subsp nana Wild, Cupressus sempervirens L., Lavandula stoechas, Lavandula angustifolia, Eucalyptus camadulensis ve Thymus vulgaris) 3 farklı dozda (\%25, \%50 ve \%100 ) larvalara uygulamışlardır. Tüm uçucu yağlar, uygulanan her üç dozda da böcek öldürücü aktivite göstermiştir. Çetin ve Yanıkoğlu (2006) çam kese larvalarına karşı uçucu yağlardan Origanum onites L. ve Citrus aurentium L.' u 3 farkl1 doz (\%0,1; \%0,5 ve \%1) topikal olarak larvalara karşı uygulamış ve çalışma sonucunda kekik yağının etkili olduğunu bildirmişlerdir. Söz konusu araştırmada, $O$. onites için $\mathrm{LD}_{50}$ ve $\mathrm{LD}_{90}$ değerlerini sırasıyla 0,288 ve 0,926 olarak hesaplamışlardır. Önemli bir orman zararlısı olan Çam kese böceği larvalarına karşı uçucu yağların uygulanması ile olumlu sonuçlar elde edilmiştir. Yapılan çalışmalar dikkate alındığ zaman, Çam kese böceği kontrolünde uçucu yağların sentetik insektisitlere potansiyel bir alternatif olabileceğini göstermişlerdir.

\section{Kaynaklar}

Abbott WS (1925). A method of computing the effectiveness of an insecticide. Journal of Economic Entomology, 18(2): 265-267.

Akkuzu, E., Selmi, E., 2002. The use of microbial control agents against Thaumetopoea pityocampa (Den. \& Schiff.). Proceedings of Pine Processionary Moth Symposium, Kahramanmaras, Turkey, pp 67-74.

Avc1 M., Ogurlu I., 2002. The importance, biology and natural enemies of the pine processionary moth (Thaumetopoea pityocampa (Schiff.)) in the Lakes District. Proceedings of Pine Processionary Moth Symposium, Kahramanmaras, Turkey, pp 28-36.

Battisti, A., Holm, G., Fagrell, B., Larsson, S., 2011. Urticating hairs in arthropods: their nature and medical significance. Annual review of entomology, 56, 203-220.

Cetın, H.., Yanıkoglu, A., 2006. A study of the larvicidal activity of Origanum (Labiatae) species from southwest Turkey. Journal Vector Ecology, 31(1): 118-122.

Ekerbicer, H., Celik, M., Aral, M., Sasmaz, S., 2002. Harmful effects of the pine processionary moth (Thaumetopoea pityocampa) on human health. Proceedings of Pine Processionary Moth Symposium, Kahramanmaraş, Turkey, pp 203-205.

Isman, M.B., 2000. Plant essential oils for pest and di- sease management. Crop Protection ,19(8-10): 603-608.

Kanat, M., Sivrikaya, F., Serez, M., A.,2002. Research on the effects of pine processionary moth (Thaumetopoea pityocampa Schiff)), Pinus brutia Ten trees and tending activities on the diameter increment of calabrian pine in Kahramanmaras, Pine Processionary Moth Symposium, Kahramanmaras, Turkey

Kanat, M., 2002. The usage of Calosoma sycophanta L (Coleoptera: Carabidae) against pine processionary moth (Thaumetopoea pityocampa Schiff) (Lepidoptera: Thaumetopoeidae) in biological control, Pine Processionary Moth Symposium, Kahramanmaras, Turkey

Kanat, M., Alma, M. H., 2004. Insecticidal effects of essential oils from various plants against larvae of pine processionary moth (Thaumetopoea pityocampa Schiff) (Lepidoptera: Thaumetopoeidae). Pest Management Science, 60(2): 173-177.

Kesdek, M., Kordali, S., Coban, K., Usanmaz, A., Ercisli, S., 2014. Larvicidal effect of some plant extracts on the pine processionary moth, Thaumetopoea pityocampa (Denis \& Schiffermuller) in laboratory conditions. Acta Sci. Pol., Hortorum Cultus 13(5) : 145-162.

Linskens, H. F., Jackson, J.F, B,1997. Modern Methods of Plant Analysis, Vol. 12: Essential Oils and waxes, Springer, Germany

Misra, G., Pavlostathis, S.G., 1997. Biodegradation Kinetics of Monoterpenes in Liquid and Soil Slurry Systems. Applied Microbiology and Biotechnology, 47(5): 572-577.

Papachristos, D.P., Karamanoli, K.I., Stamopoulus, D., Spiroudi, U.M., 2004. The Relationship the Chemical composition of Three Essential Oils and their Insecticidal Activity Against Acanthoscelides obtectus. Pest Management Science, 60(5): 514-520.

Petrakis, P. V., 2005. The effect of terpenoid extracts from 15 pine species on the feding. behavioural sequence of the late instars of the pine processionary caterpillar Thaumetopoea pityocampa." Behavioural Processes, 69(3) :303-322.

Rabenhorst, J., 1996. Production of MethoxyphenolType Natural Aroma Chemicals by Biotransformation of Eugenol with a New Pseudomonas sp. Applied Microbiology and Biotechnology, 46: 470-474.

Yiğit, Ş., Saruhan, İ., Akça, İ., 2019a. The effect of some commercial plant oils on the pine processionary moth Thaumetopoea pityocampa (Lepidoptera: Notodontidae). Journal Forest Science, 65: 309-312.

Yiğit, Ş., Akça, İ., Bayhan, E., Bayhan, S., Tekin, F., Saruhan, İ. 2019 b.Determining the Toxicity of Some Thyme Essential Oils Against the Pine Processionary [Thaumetopoea pityocampa (Lepidoptera: Notodontidae)], Atatürk Üniv. Ziraat Fak. Derg., 50 (3): 226-230. 